\title{
The Ocean Carbon States Database: a proof-of-concept application of cluster analysis in the ocean carbon cycle
}

Rebecca Latto and Anastasia Romanou

Correspondence to: Rebecca Latto (r12797@columbia.edu)

The copyright of individual parts of the supplement might differ from the CC BY 4.0 License. 


\section{S3. Methodology}

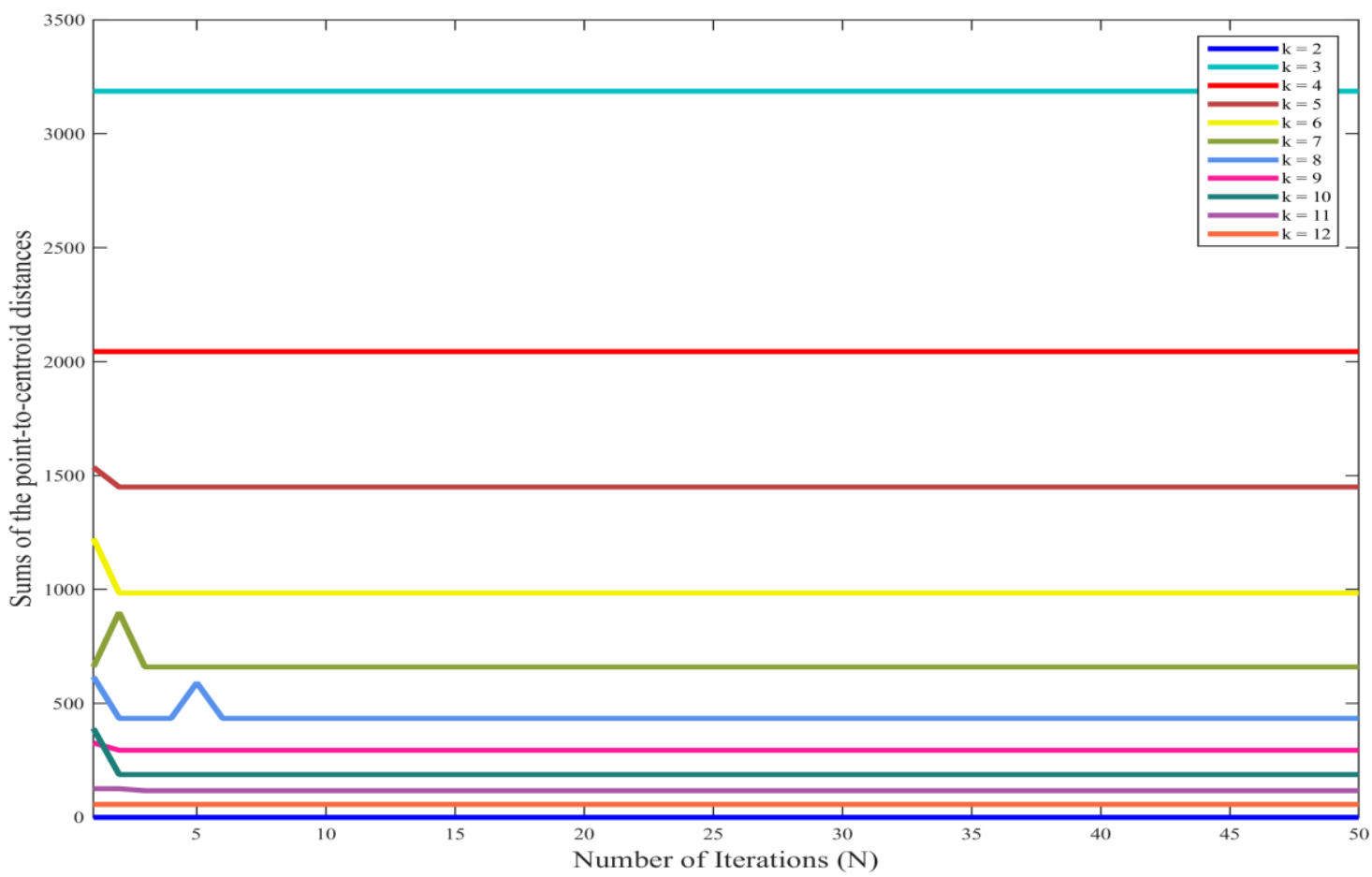

Fig. S1: Convergence test that shows the number of iterations needed so that clusters are unchanged. Each clustering analysis is performed for a different number of predetermined clusters $(k)$ and is deemed as converging when the sum of the distances between each member 2D histogram from the cluster centroid is no longer changing. Convergence is tested for different number of predetermined clusters, $k=1, k=2, \ldots, k=12$. We find that less than 10 iterations are needed to obtain convergence. 


\section{S4. Results}

\section{S4.1 The North Atlantic Ocean Carbon States}
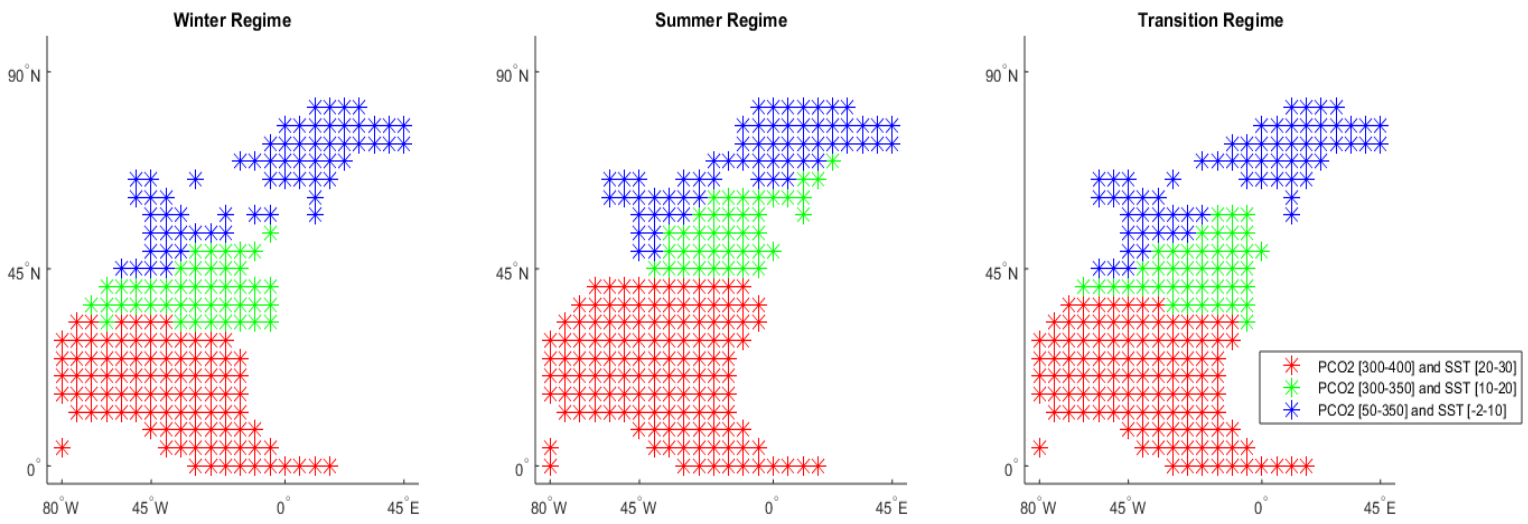

Fig. S2: Demarcated regions within the North Atlantic basin defined by ranges of $\mathrm{pCO}_{2 \mathrm{Sw}}$ and SST values in the observed ocean 5 carbon states.

a)
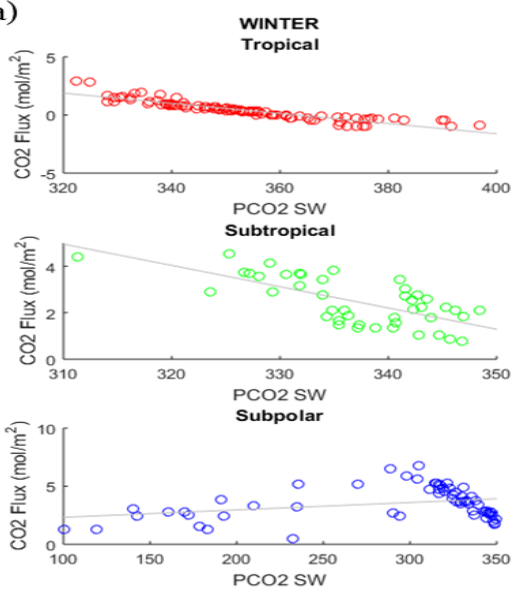

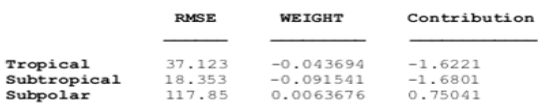
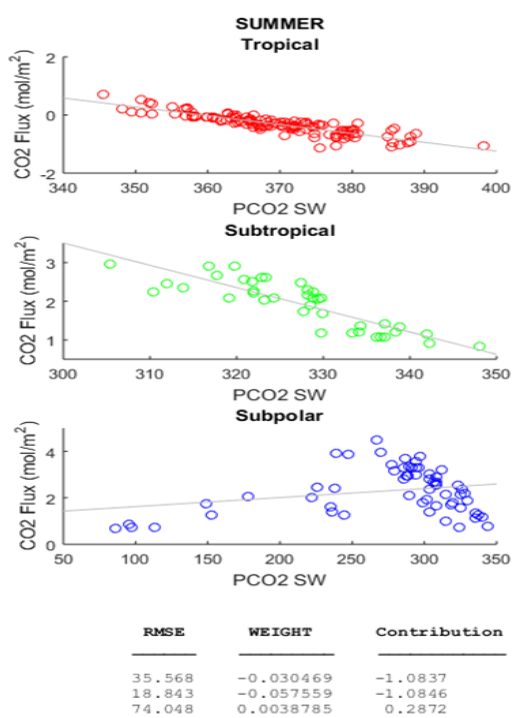
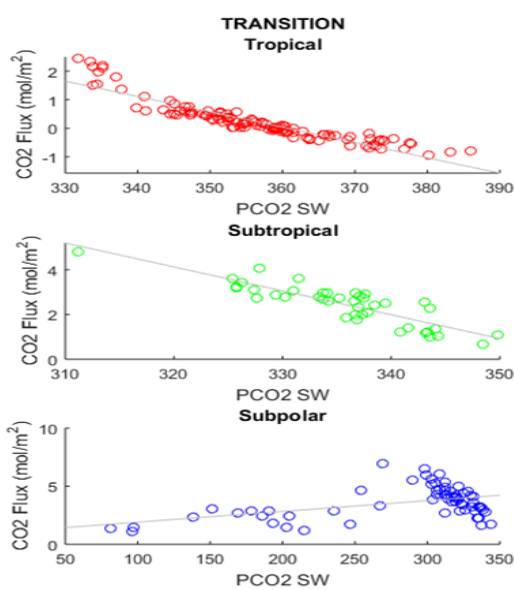

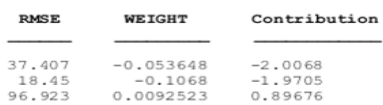


b)
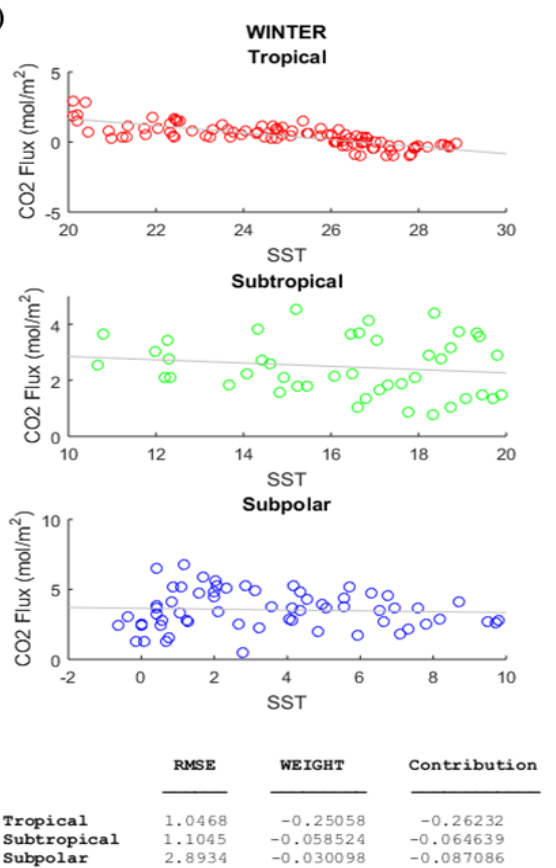

c)
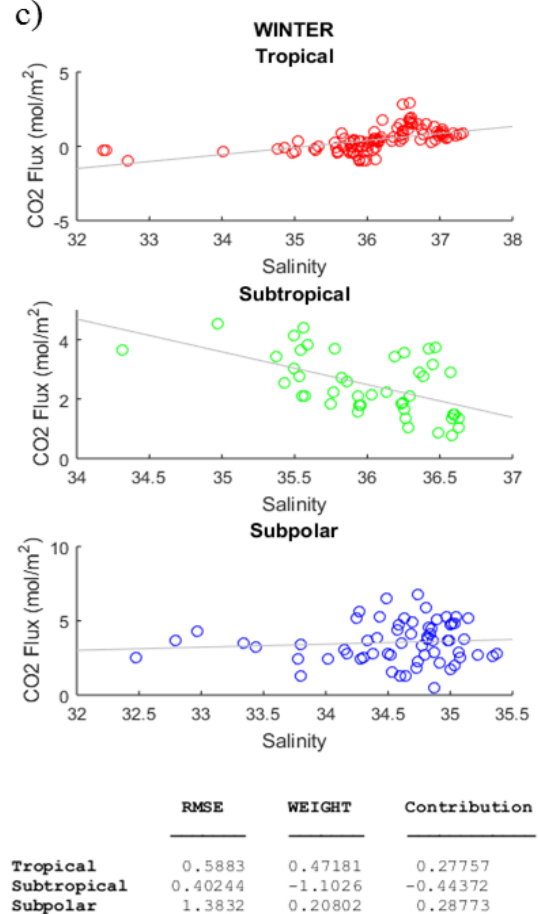

SUMMER
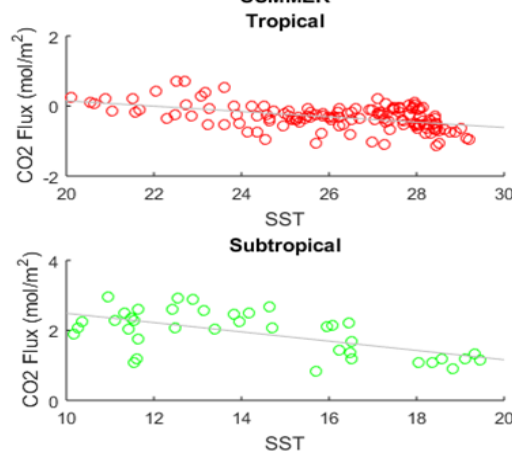

Subpolar
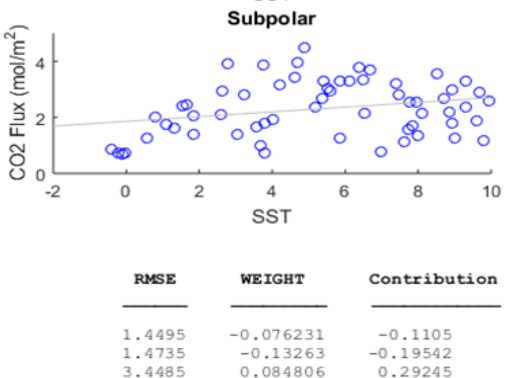

SUMMER
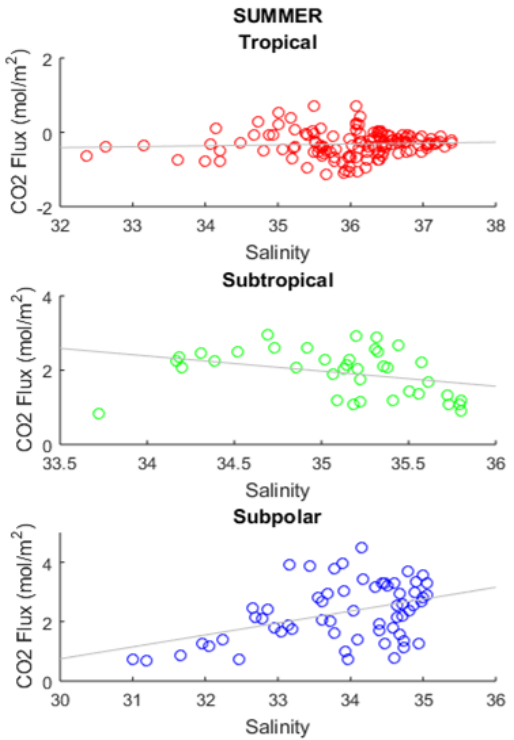

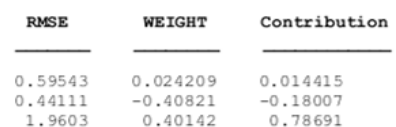

TRANSITION

Tropical
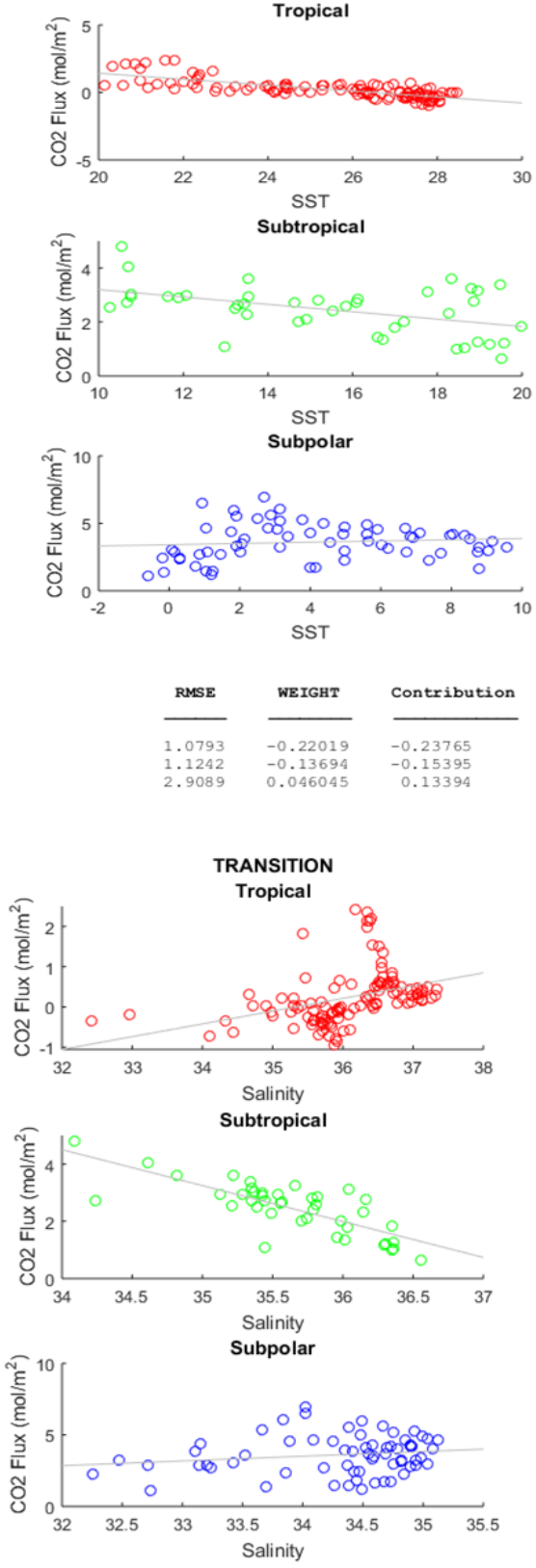

RMSE WEIGHT Contribution

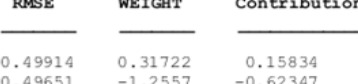

$0.49659--1.2557$ 
d)
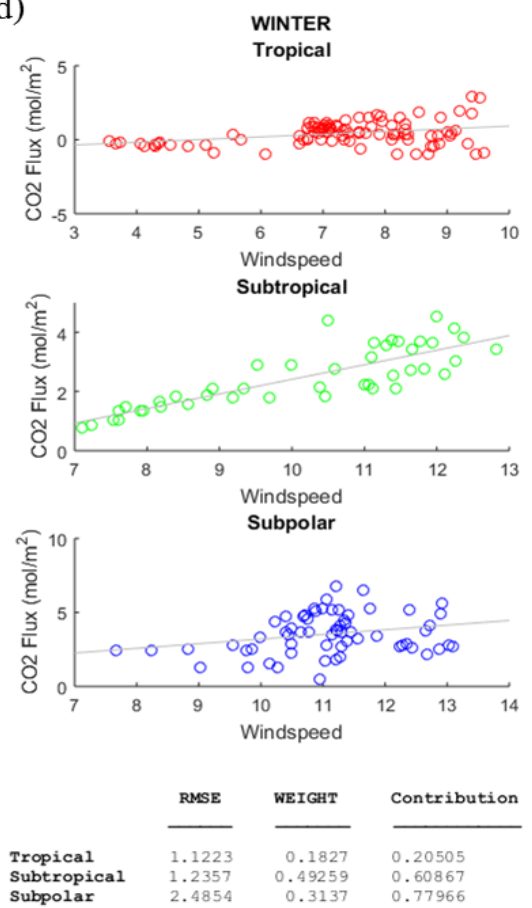

SUMMER
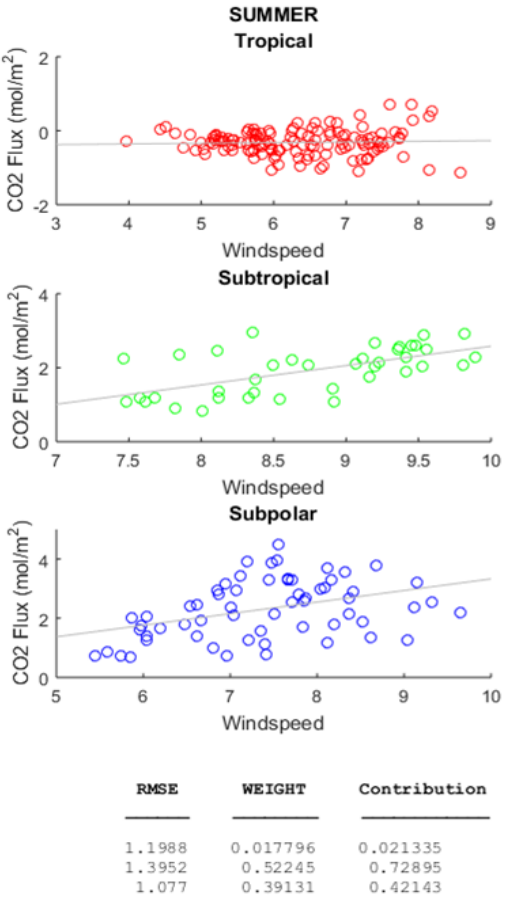
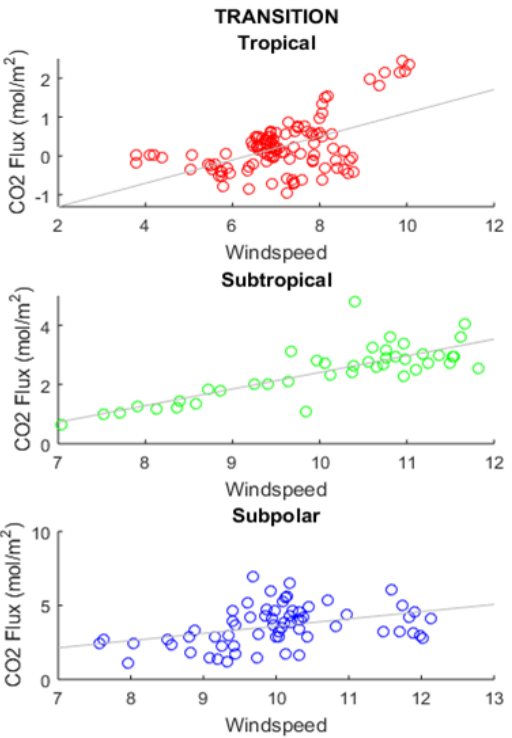

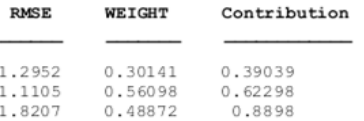

Fig. S3: Scatter diagrams and linear fits of the air-sea flux of $\mathrm{CO} 2$ with a) pCO2 $\mathrm{Sw}$, b) SST, c) salinity, and d) wind speed in each of the North Atlantic regions that is represented in each regime. The regions are also shown in Fig. S2. The RMSE terms are the bias terms denoted as $\Delta q$ and the weight terms are the $\frac{\partial F}{\partial q}$ terms in Eq. (5). The contribution terms are the products of each bias*weight 5 terms in Eq. (5). 
a)
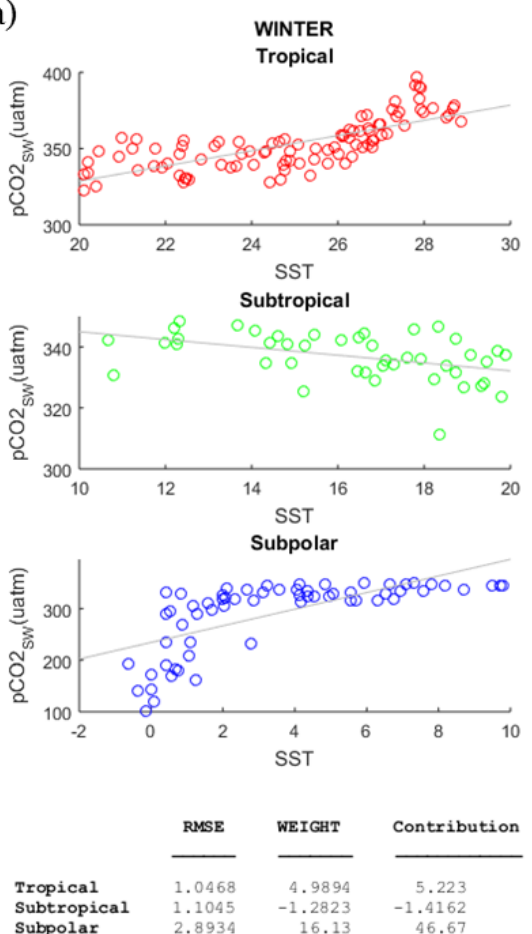

b)
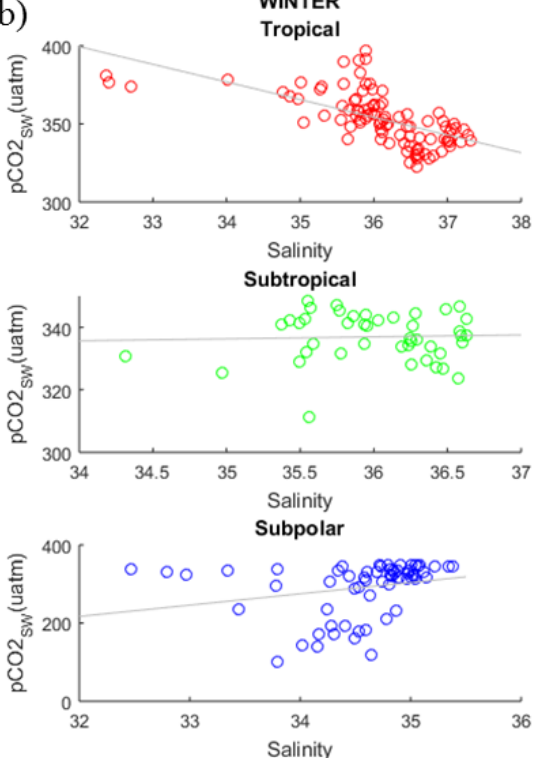

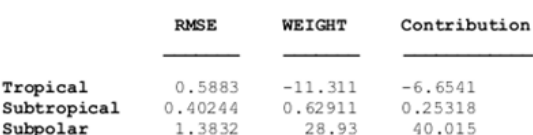

SUMMER

Tropical
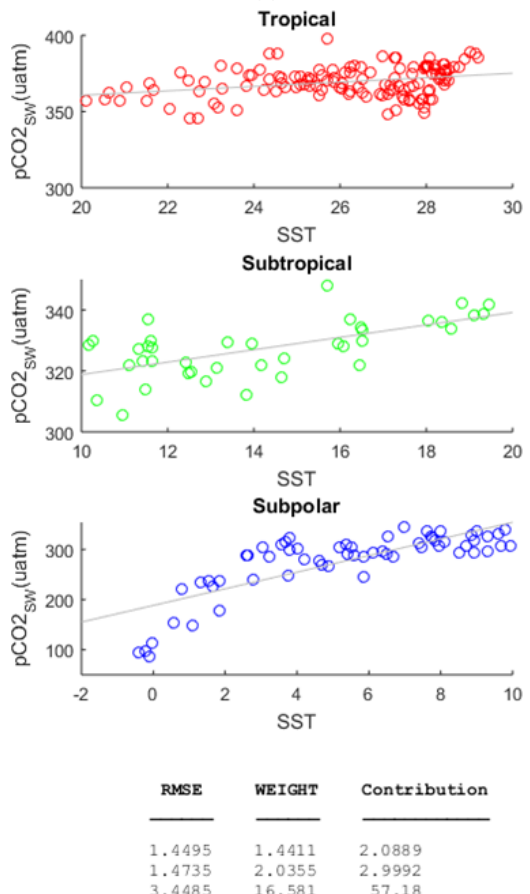

$\begin{array}{rrr}1.4735 & 2.0355 & 2.9992 \\ 3.4485 & 16.581 & 57.18\end{array}$
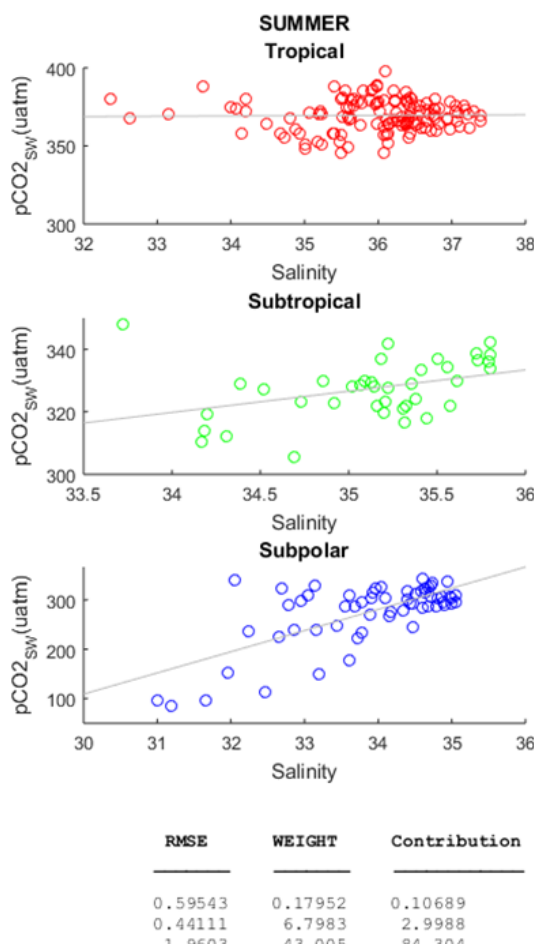

TRANSITION

Tropical
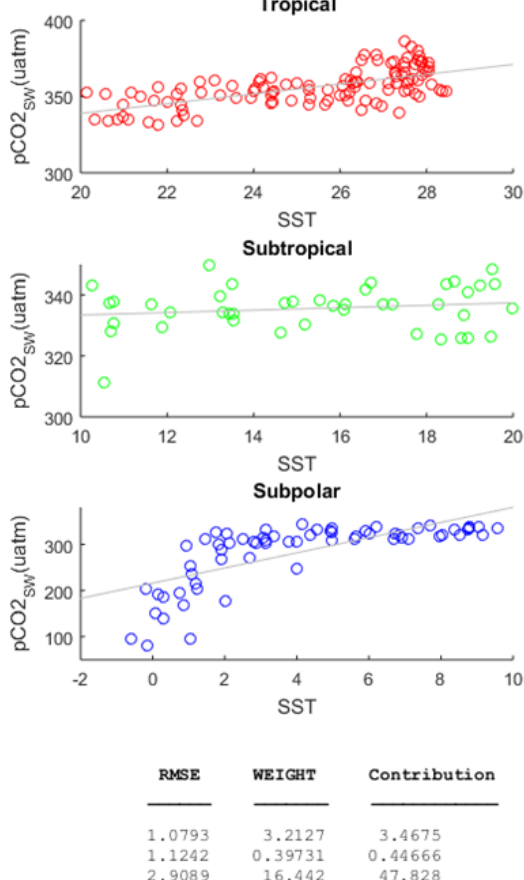

$\begin{array}{ll}1.1242 & 0.39731 \\ 2.9089 & 16.442-47.828\end{array}$
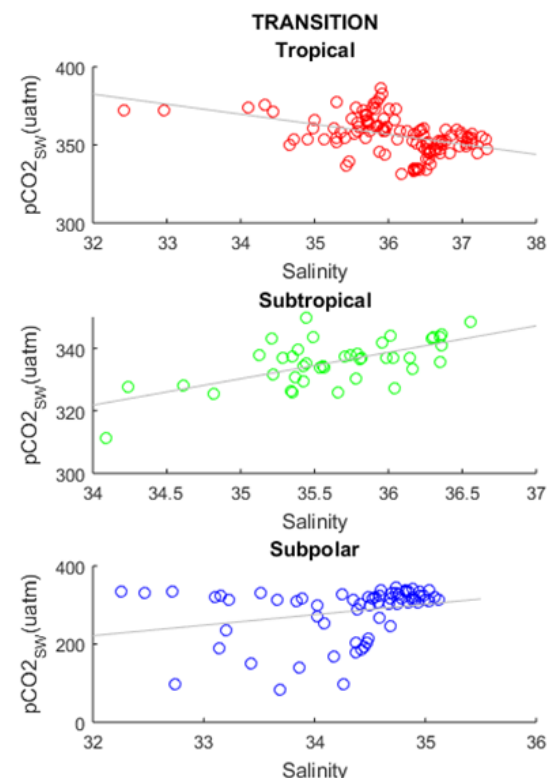

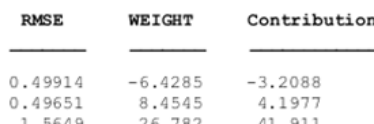


c)
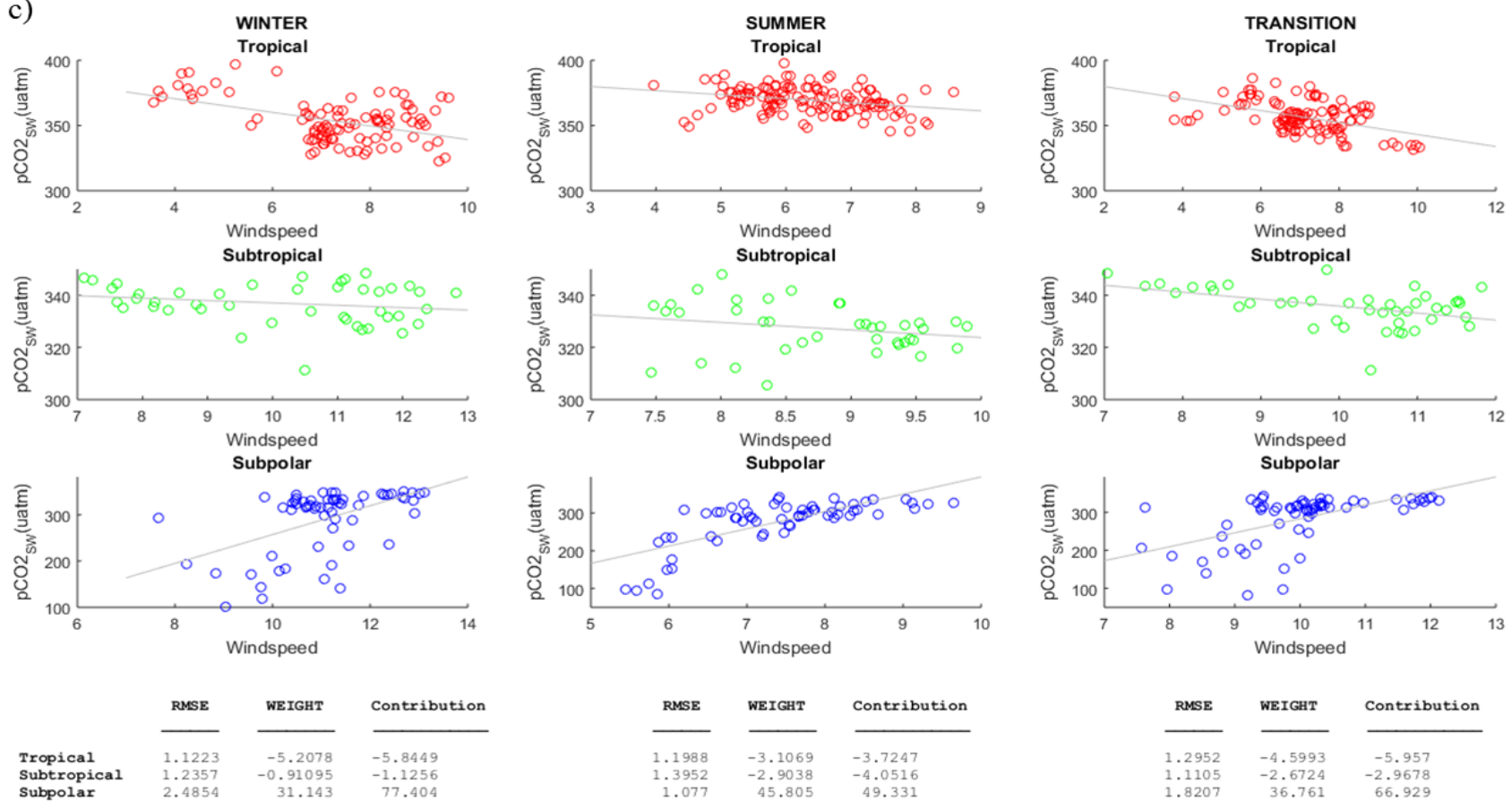

d)
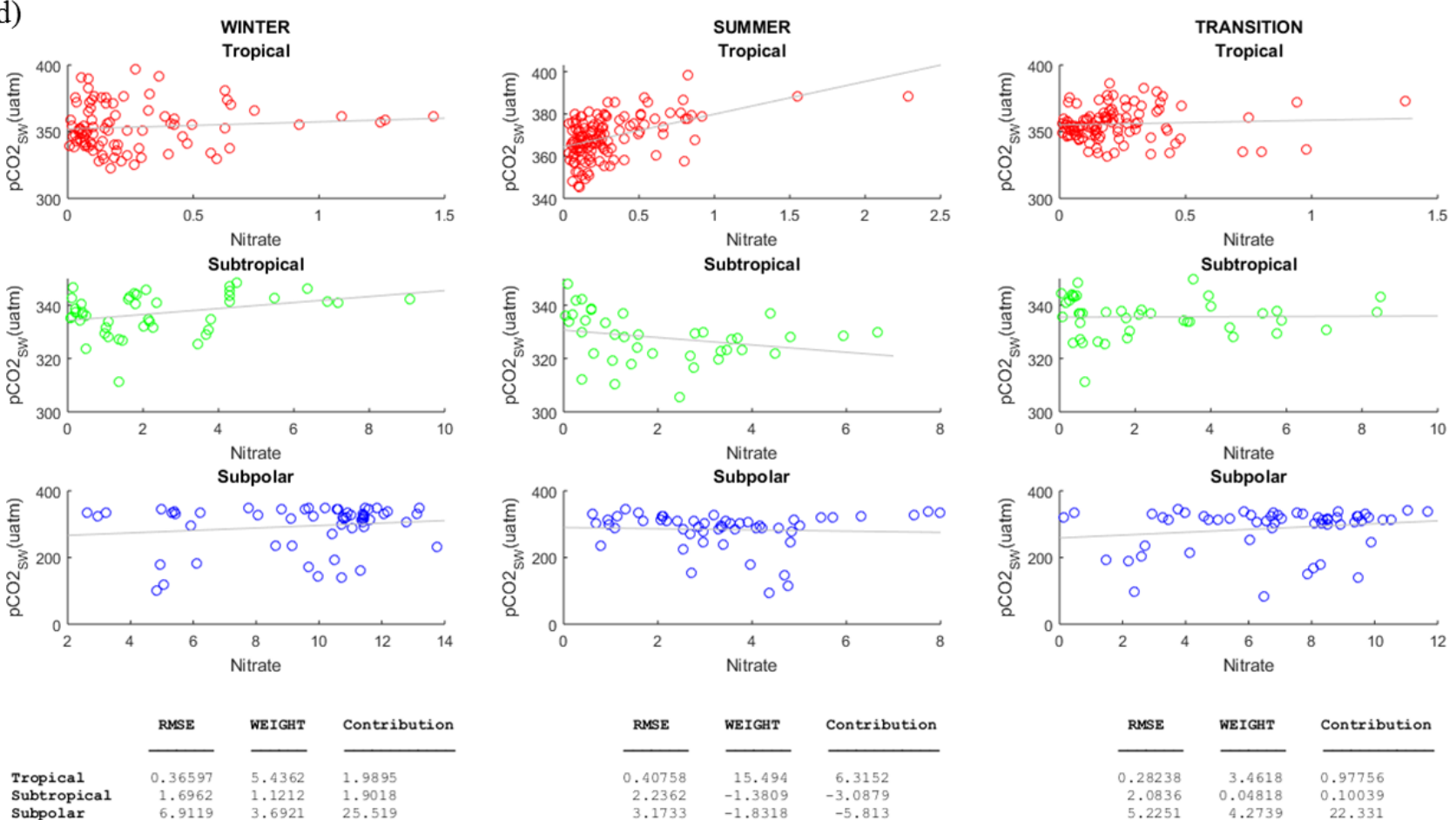

Fig. S4: Scatter diagrams and linear fits of pCO2sw with a) SST, b) salinity, c) wind speed and d) nitrate in each of the North Atlantic regions of each regime. 


\section{S4.2 The Southern Ocean Carbon States}
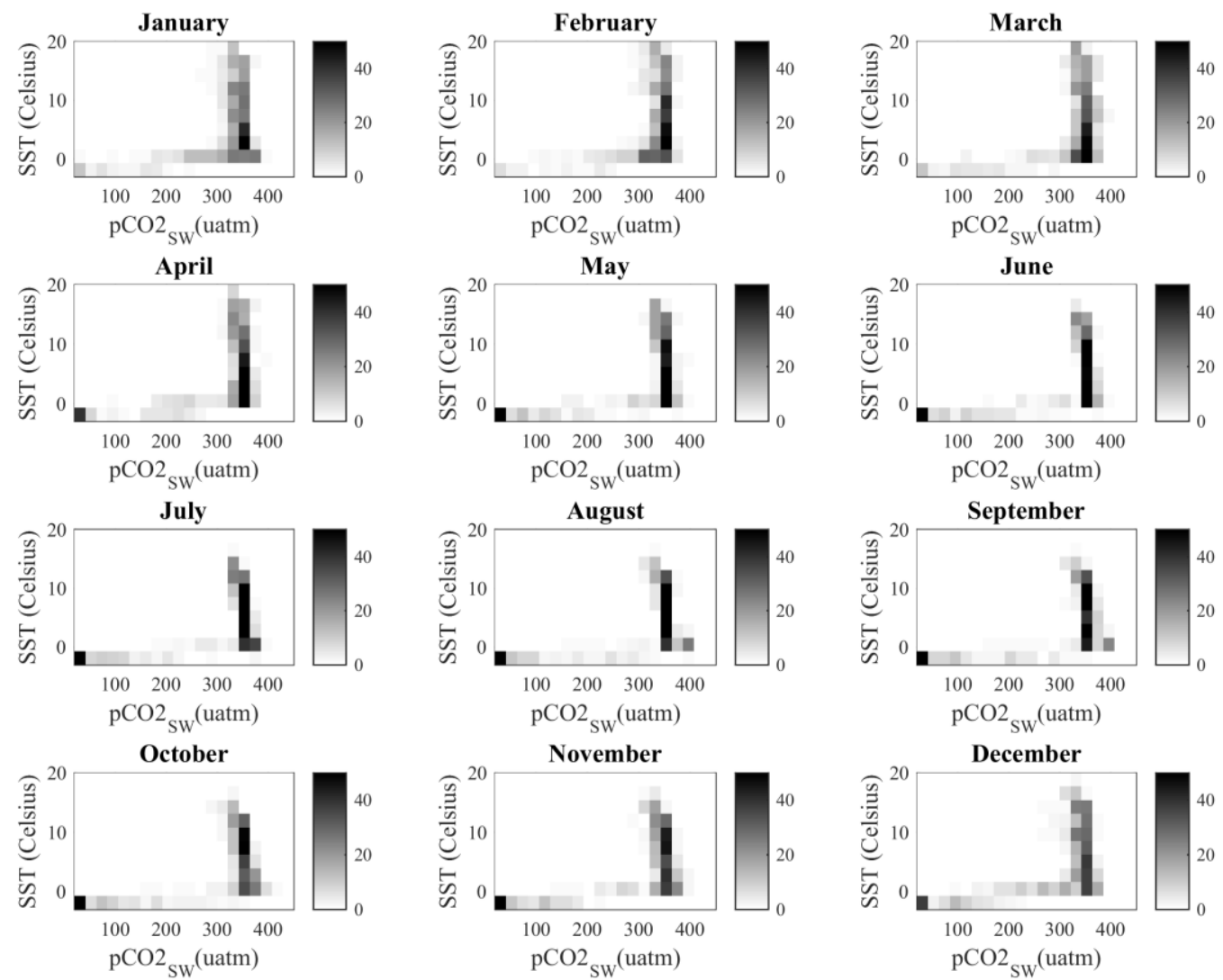

Fig. S5: Monthly 2D histograms of pCO2 of surface water (pCO2sw) and SST in the Southern Ocean (defined as $180^{\circ} \mathrm{W}$ to $180^{\circ} \mathrm{E}$, $90^{\circ} \mathrm{S}$ to $40^{\circ} \mathrm{S}$ ) from the Takahashi observational dataset. 


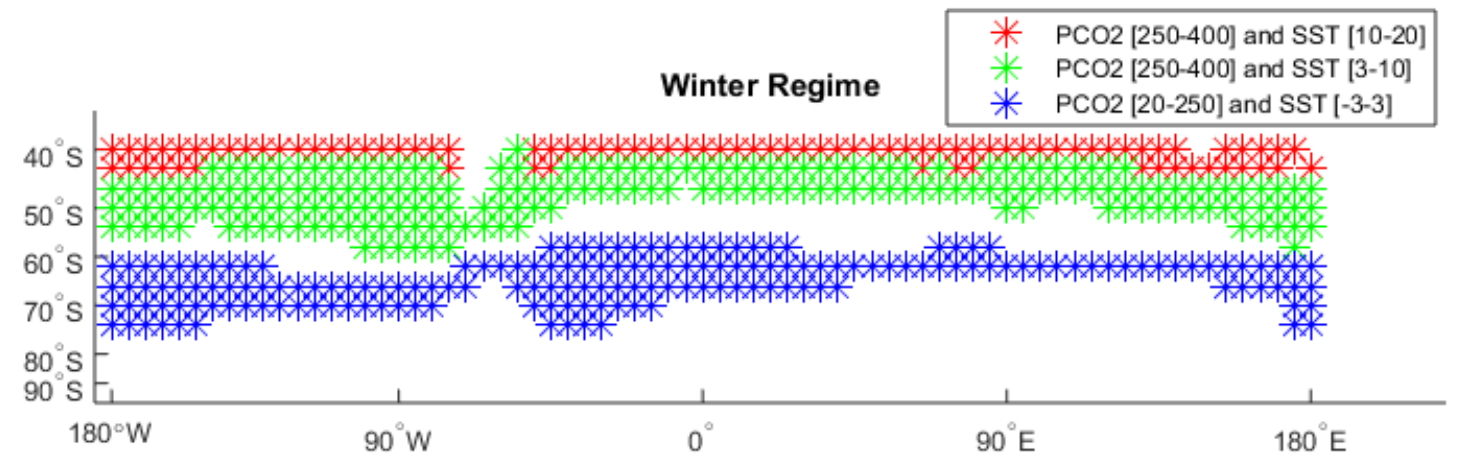

Summer Regime
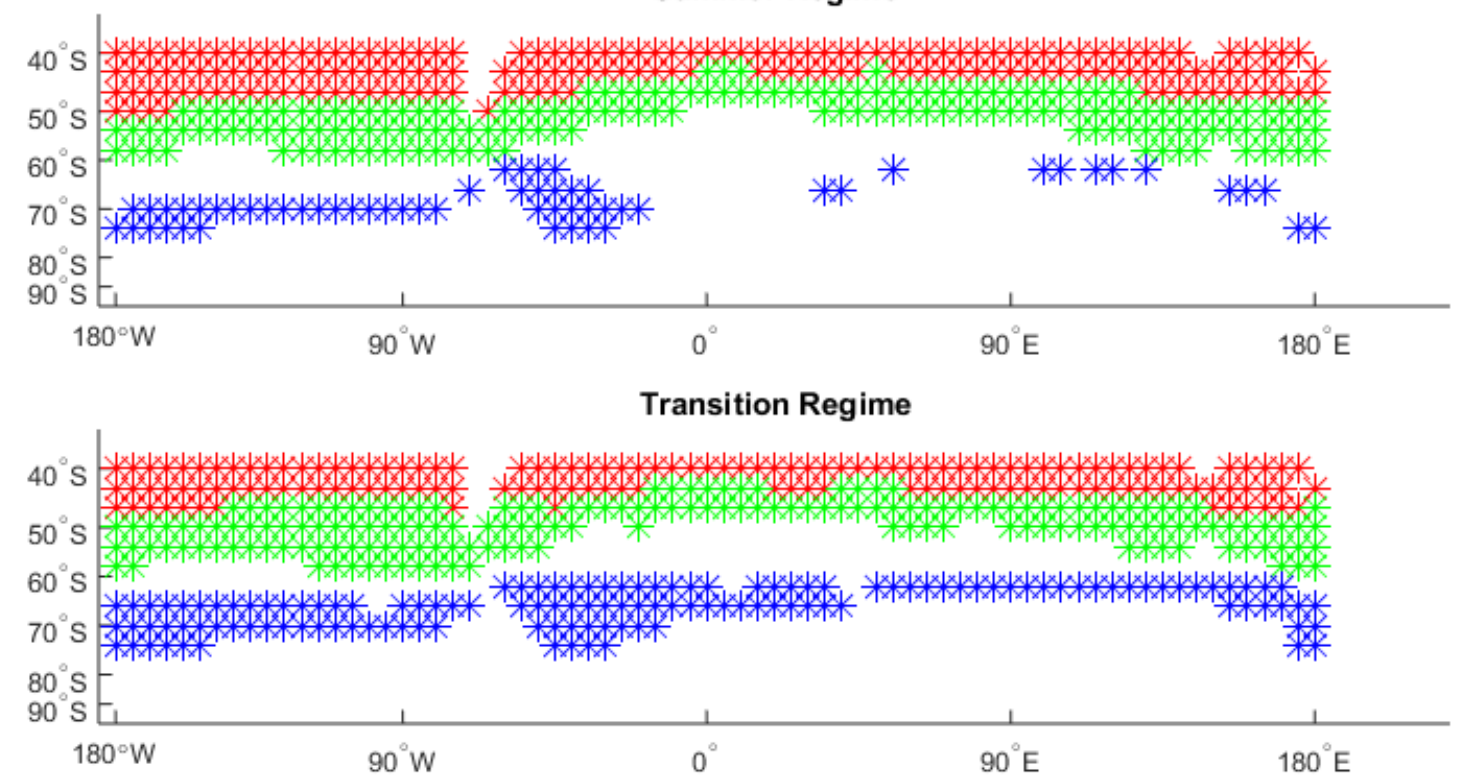

Fig. S6: Demarcated regions within the Southern Ocean basin defined by ranges of $\mathrm{pCO}_{2 \mathrm{Sw}}$ and SST values. The choice of the regions is based on the dominant bins in each ocean carbon state. 

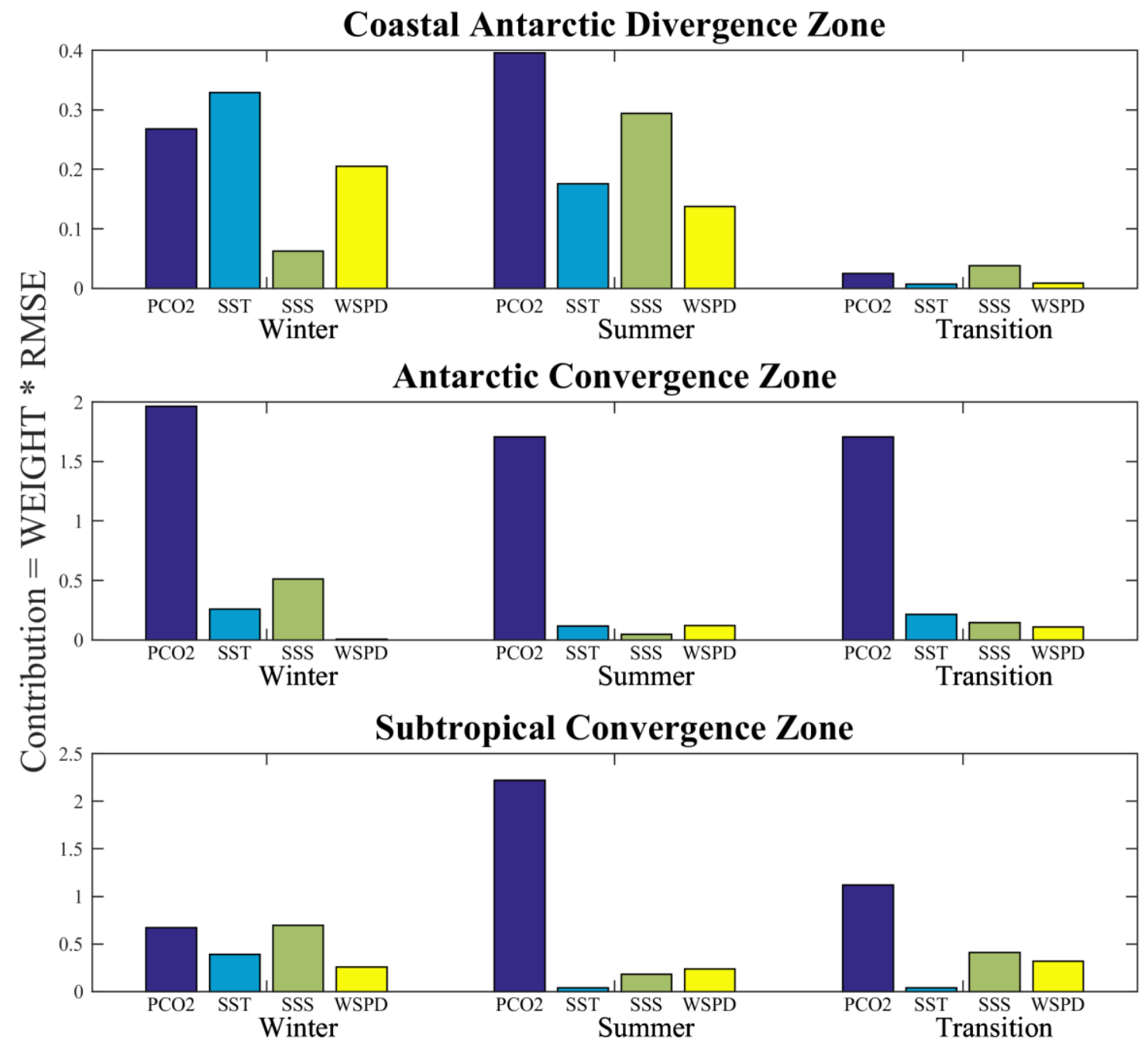

Fig. S7: Bias terms as computed in the Taylor expansion of the model bias for the air-sea flux of $\mathrm{CO} 2$. 
a)
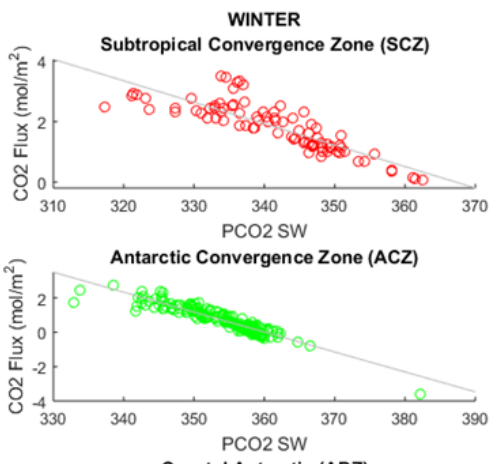

Coastal Antarctic (ADZ)

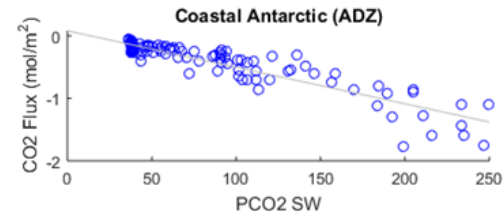

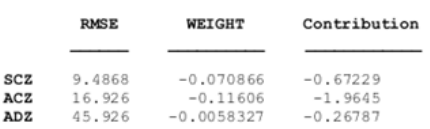

b)
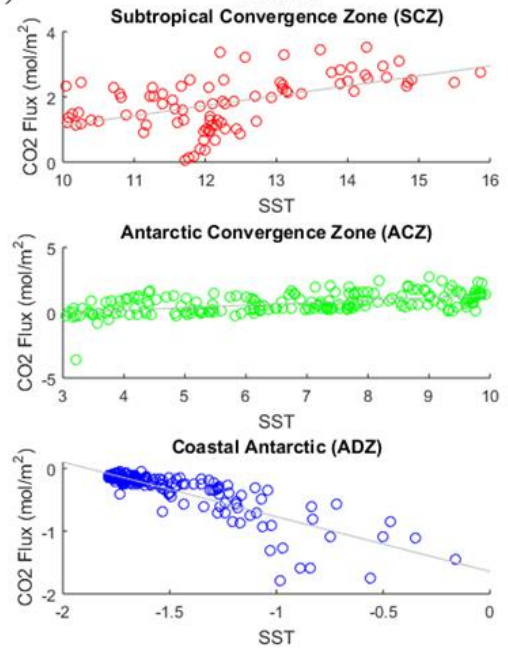

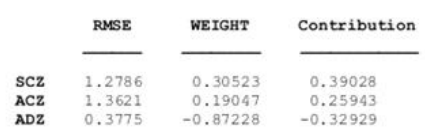

SUMMER
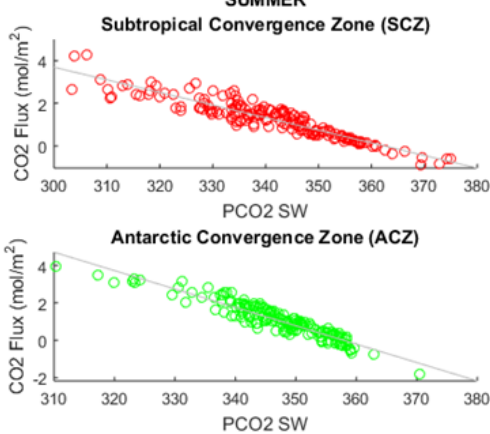

Coastal Antarctic (ADZ)

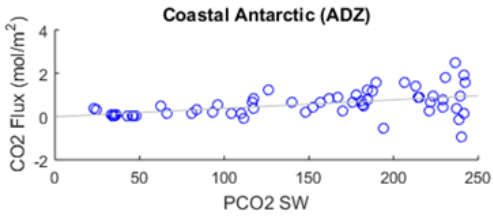

\begin{tabular}{|c|c|c|}
\hline RMSE & WEIGHT & Contribution \\
\hline 9.593 & -0.059088 & -2.22 \\
\hline 17. & -0.098416 & -1.7061 \\
\hline 101.05 & 0.0039145 & 0.39556 \\
\hline
\end{tabular}

SUMMER
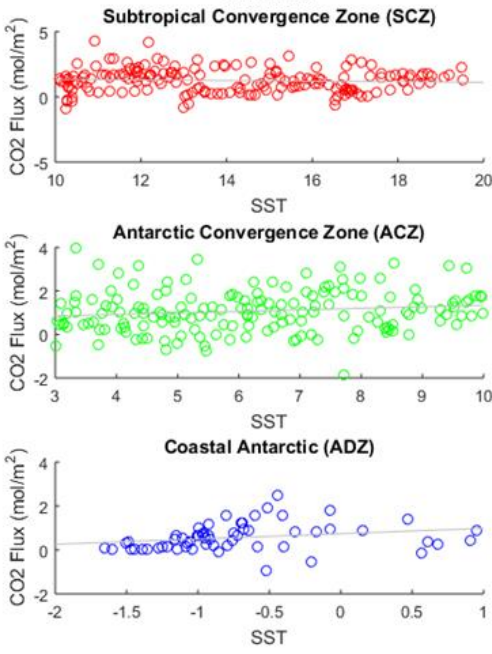

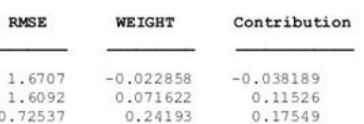

TRANSITION
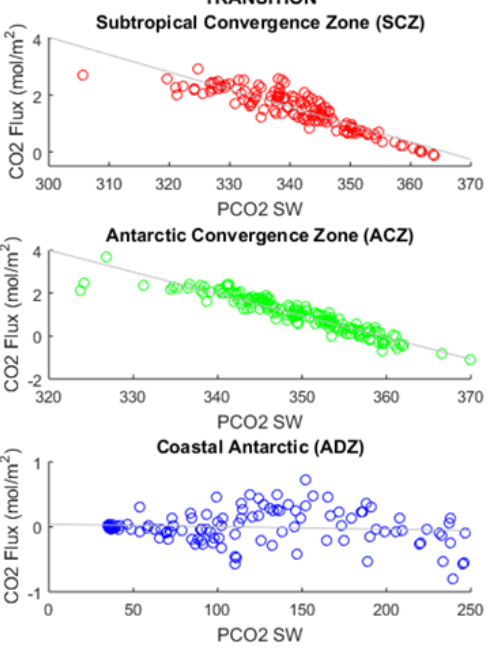

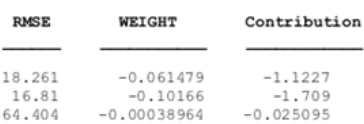
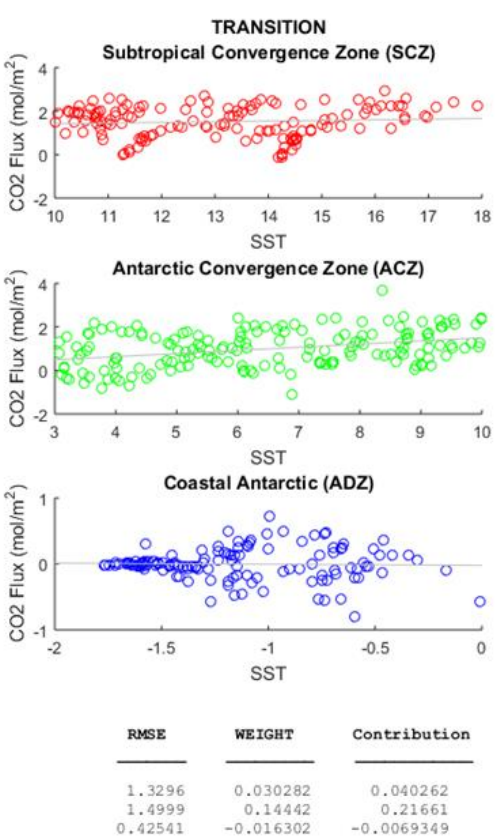
c)
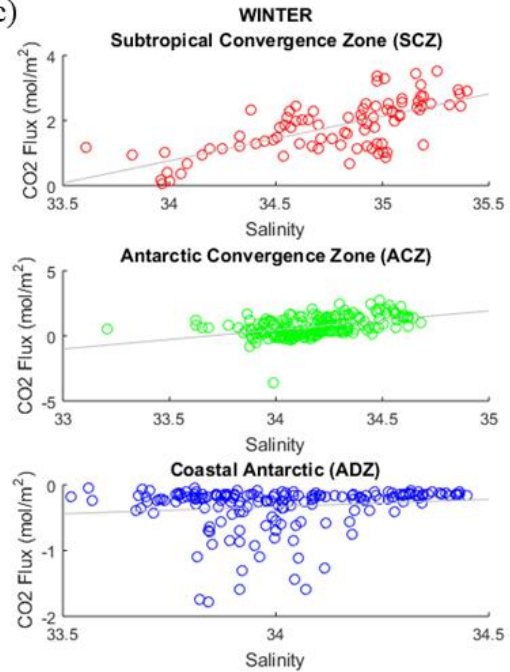

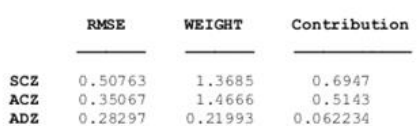

d)
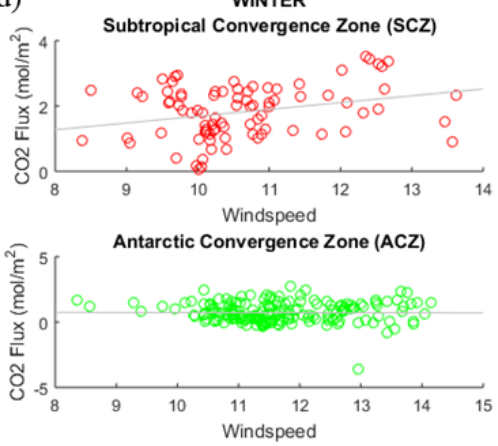

Coastal Antarctic (ADZ)
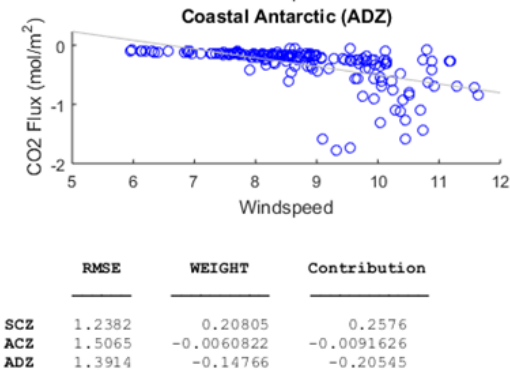

SUMMER
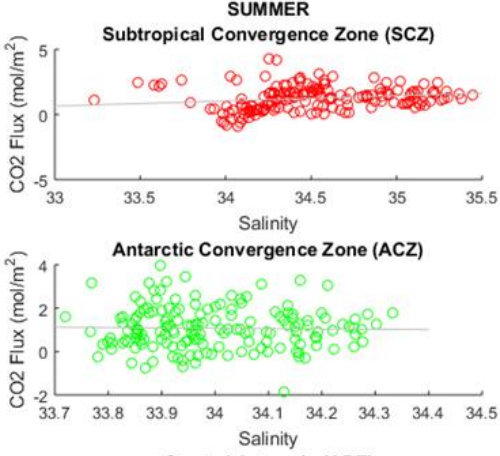

Coastal Antarctic (ADZ)
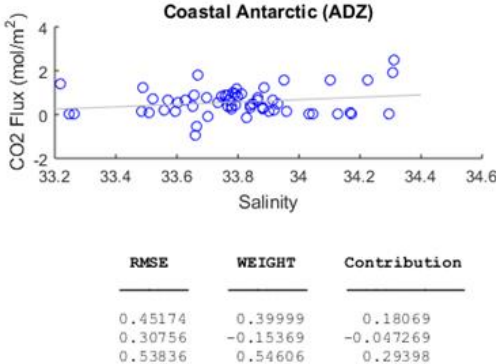

SUMMER
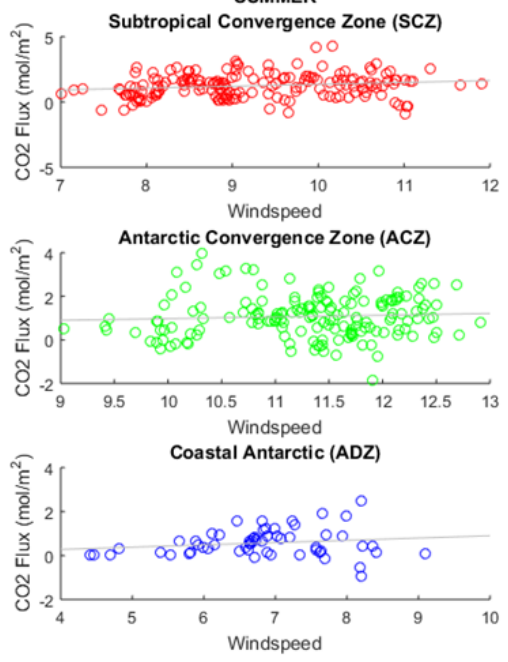

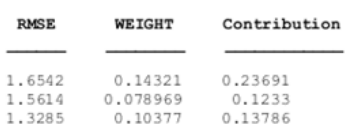

TRANSITION
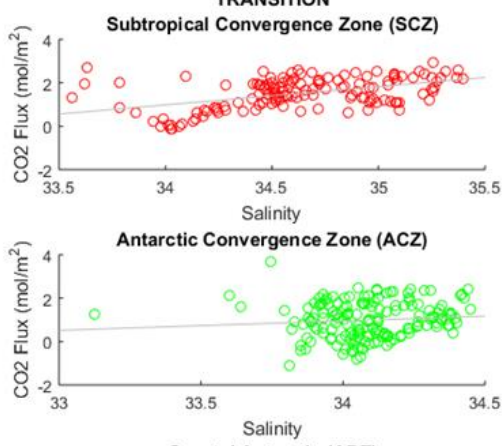

Coastal Antarctic (ADZ)
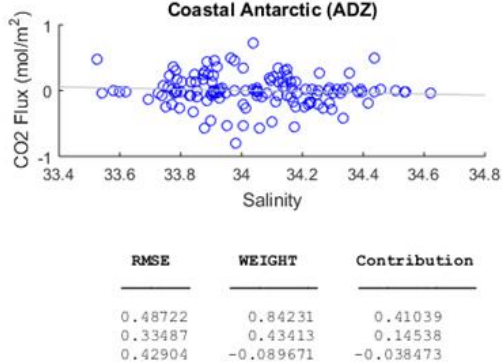

TRANSITION
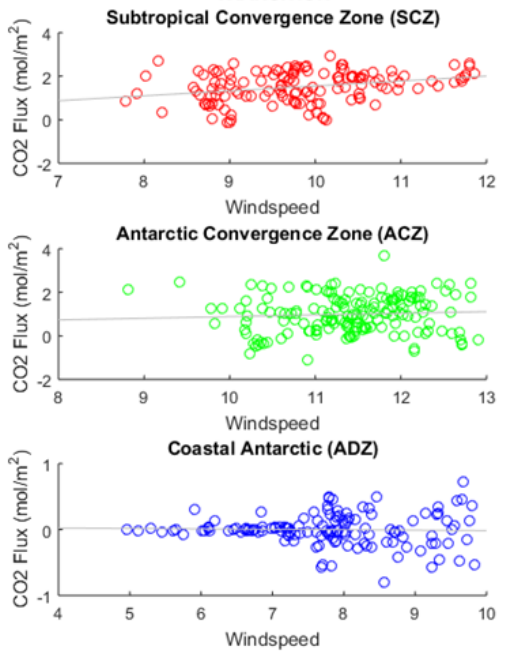

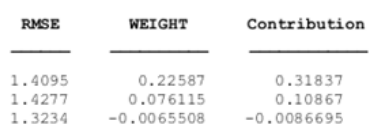

Fig. S8: Scatter diagrams and linear fits of the air-sea flux of $\mathrm{CO}_{2}$ with a) $\mathrm{pCO}_{\mathrm{sw}}$, b) SST, c) salinity, and d) wind speed in each of the Southern Ocean regions and for each regime. 
a)
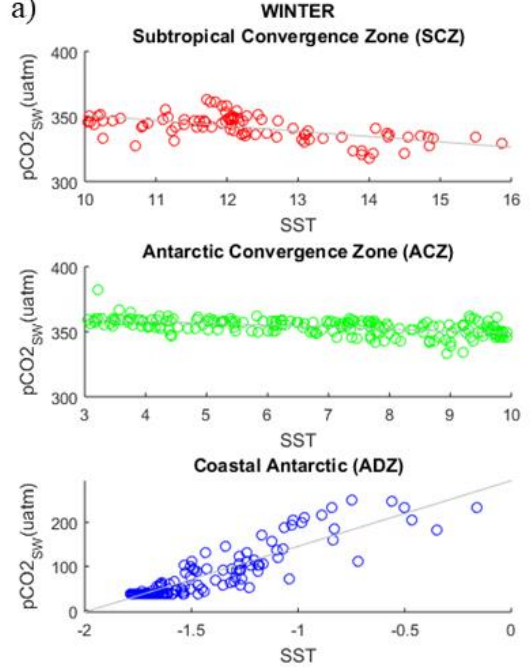

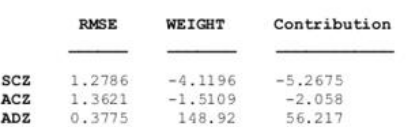

b) WINTER
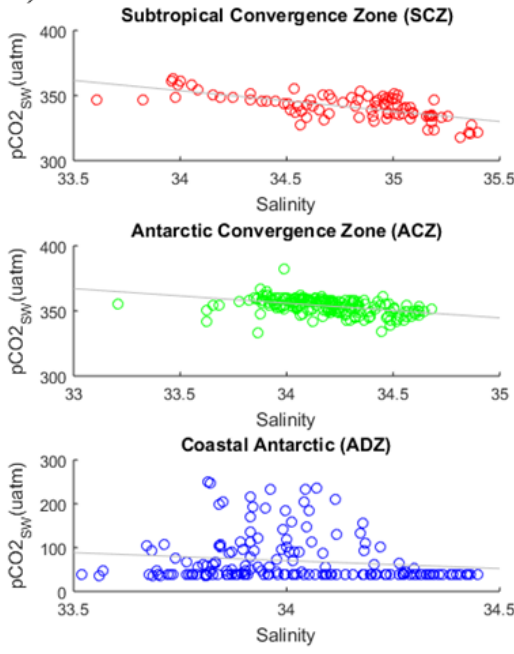

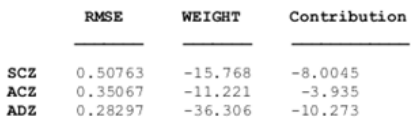

SUMMER

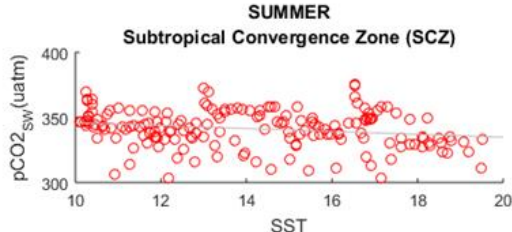

Antarctic Convergence Zone (ACZ)

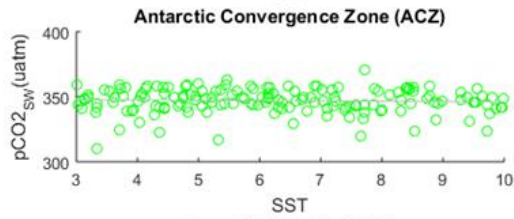

Coastal Antarctic (ADZ)

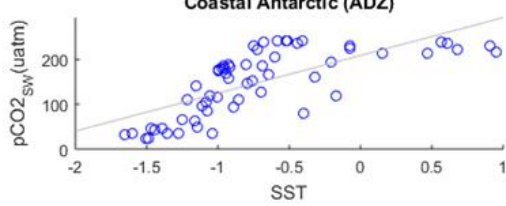

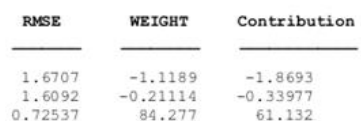

SUMMER
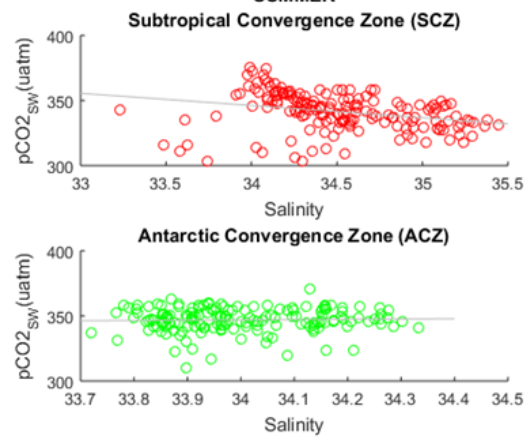

Coastal Antarctic (ADZ)

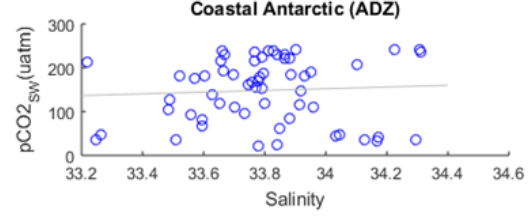

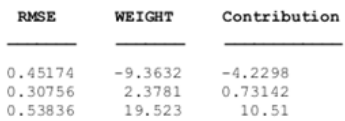

TRANSITION

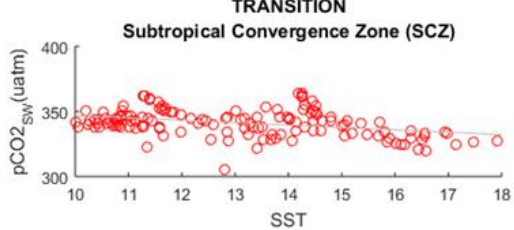

Antarctic Convergence Zone (ACZ)

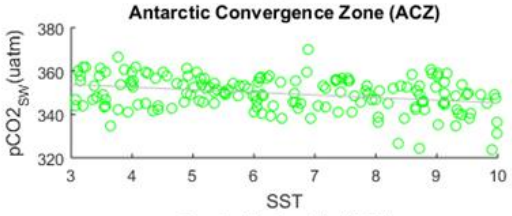

Coastal Antarctic (ADZ)

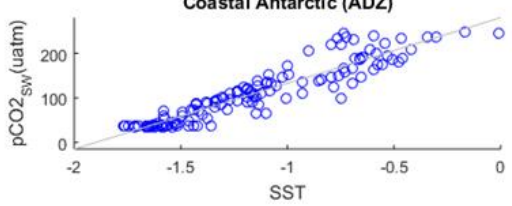

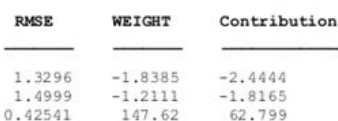
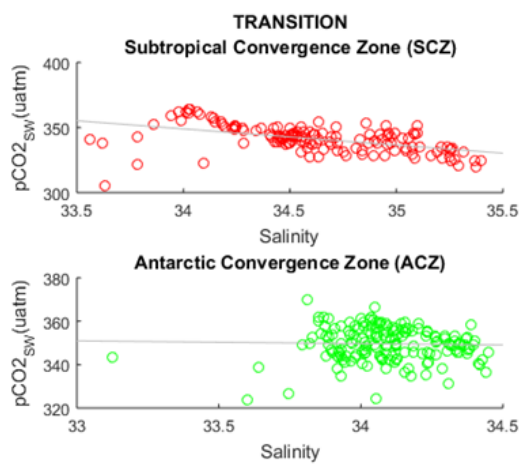

Coastal Antarctic (ADZ)

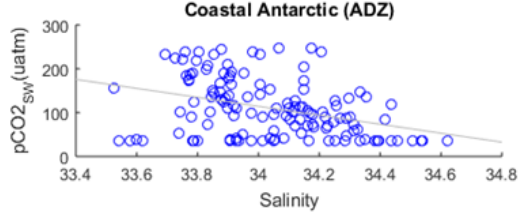

RMSE WEICHT

WEIGHT Contribution

$\begin{array}{lll}0.48722 & -12.445 & -6.0635 \\ 0.33487 & -1.2514 & -0.42907\end{array}$

$\begin{array}{lll}0.33487 & -1.2514 & -0.41907\end{array}$ 
c)
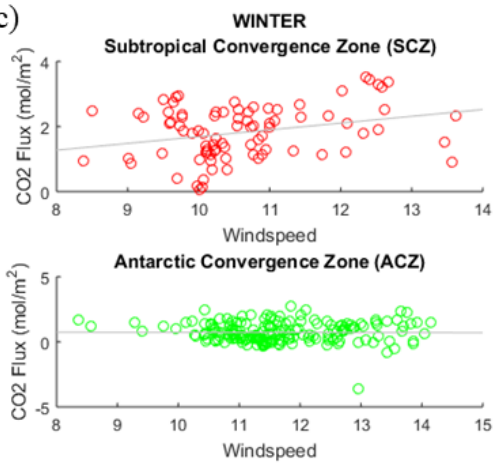

Coastal Antarctic (ADZ)

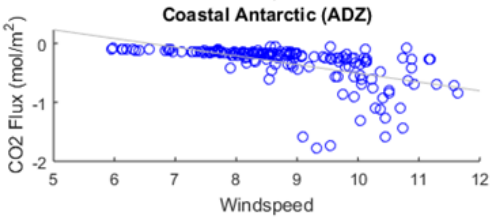

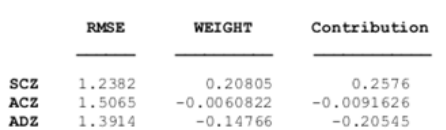

d)
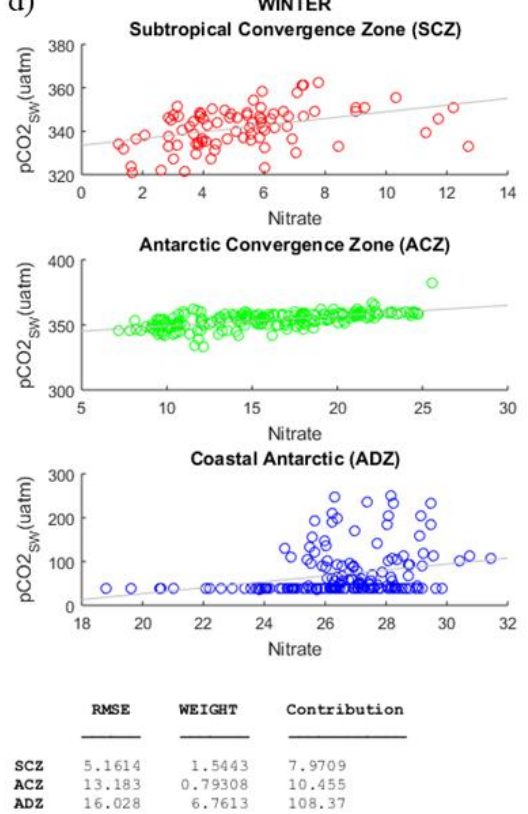

SUMMER
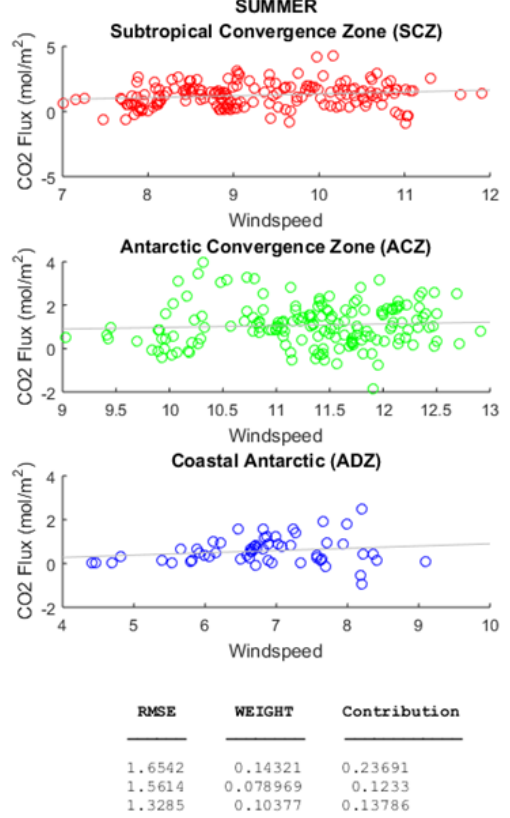

SUMMER
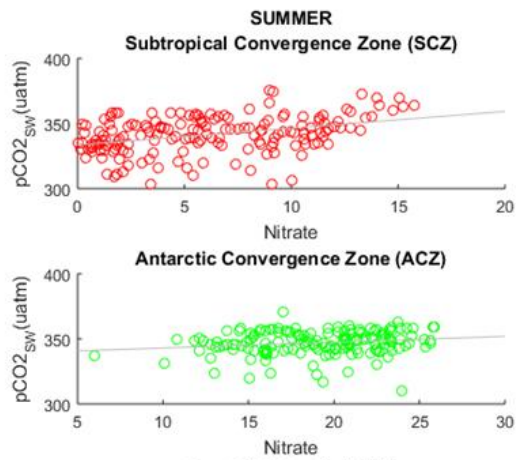

Coastal Antarctic (ADZ)
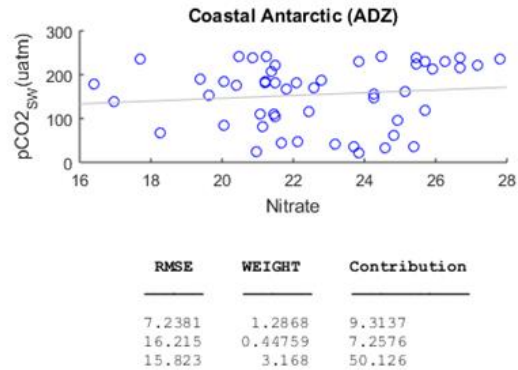

TRANSITION
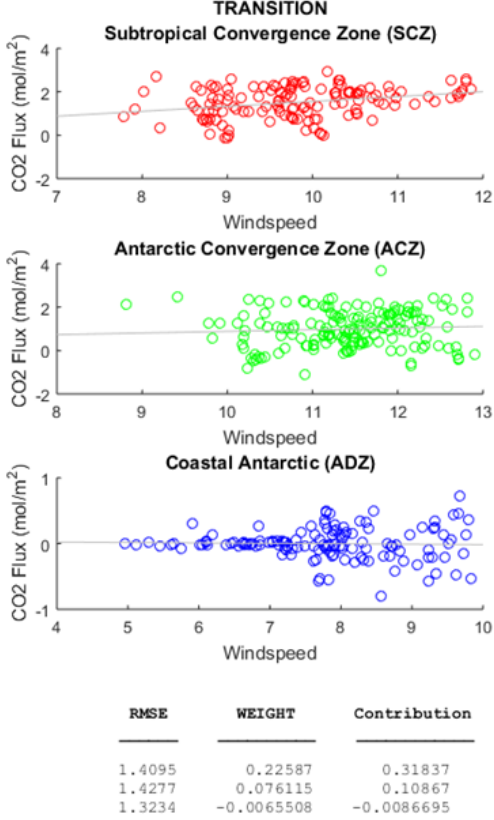

TRANSITION
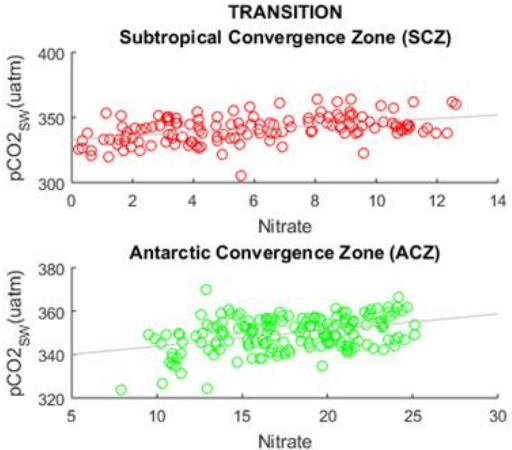

Coastal Antarctic (ADZ)

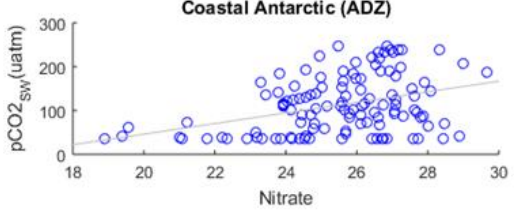

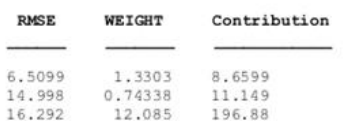

Fig. S9: Scatter diagrams and linear fits of pCO2sw with a) SST, b) salinity, c) wind speed and d) nitrate in each of the Southern Ocean regions and for each regime. 